\title{
DETERMINING THE STABILITY CONDITIONS OF THE TRACK-DRIVEN VEHICLE WHILE STAIR CLIMBING AND DESCENDING
}

\author{
Pham Duc Khoi, Thai Thi Thu Ha \\ DCSELAB, University of Technology, VNU-HCM \\ (Manuscript Received on April $5^{\text {th }}$, 2012, Manuscript Revised November 20 ${ }^{\text {rd }}$, 2012)
}

ABSTRACT: This article presents the method of determining the stability limit of the vehicle (robots or electric wheelchairs) that use tracks (chain, belt) for climbing and descending stairs. Research method was conducted by modeling vehicle which is working under the influence of some elements such as geometric, mass, velocity, acceleration, friction...Afterthat, we identify some conditions which lead to tipping. Finally, the results of research are constraint equations in order to ensure stable operation of vehicle.

Keywords: wheelchair.

\section{INTRODUCTION}

Nowadays, there are many kinds of mobile robots which have been used in different tasks. One of the most interesting and useful mobile robots is mobiles robot capable of climbing and descending stairs. They are powered wheelchair which greatly improve the mobility of people with disability, the robot security, reconnaissance, fire ...

There were many types of vehicle have been developed and still are under development to make a mobile robot capable of climbing and descending steps, slopes and stairs. The popular solutions make use of tracks, clusters of wheels, legged system.

The legged systems are mentioned in [1]. Legged robots are versatile for obstacle overpassing and high mobility in difficult terrain or soil condition, but they are too complex, low speed, and low-load capacity.
An alternative solution consists of a cluster of wheels that are attached to a rotating link. A commercial available stairs-climbing wheelchair is shown in [2] where the wheel has a smaller radius of ladder height. Each cluster is combined from two or more wheels, are arranged beam (star). Each wheel within a wheel spindle beam separately. Indeed, there are several problems in using cluster of wheels. A problem concerns with that each wheel of a cluster must have its own transmission system, and therefore a vehicle can be very heavy, large size, high energy consumption.

Track is a quite common solution. A track is an endless belt or chain in self-propelled vehicle, and it helps the vehicle to distribute its weight more evenly over a larger surface area than wheels contacts only. In obstacle climbing, tracks emulate a wheel with infinite radius so that an obstacle can be over passed as 
a slope by using track extension as bridge. A high friction coefficient between step edge and track is also needed to generate a proper tangential force that allows the vehicle to climb an obstacle. An example of using tracks in climbing and descending stairs is Top-chairs, the principles presented in [3], illustrated in Figure 1. This vehicle has two pairs of tracks that can adapt their geometry to the initial and final phases in climbing and descending stairs.

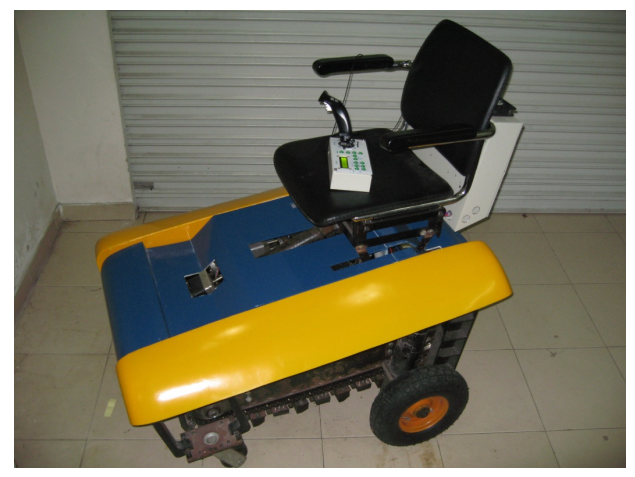

Figure 1. Top-chairs vehicle.

The next section will present the research methods of stability of vehicles that climb and descend steps by using tracks, reference to [4].

\section{MODELING}

Elements to be considered include the geometrical elements (dimensions and shape of the vehicle, the size of the stairs), the statistical elements (mass and inertia), the kinematical element (velocity and acceleration), the dynamical elements (forces and moments).

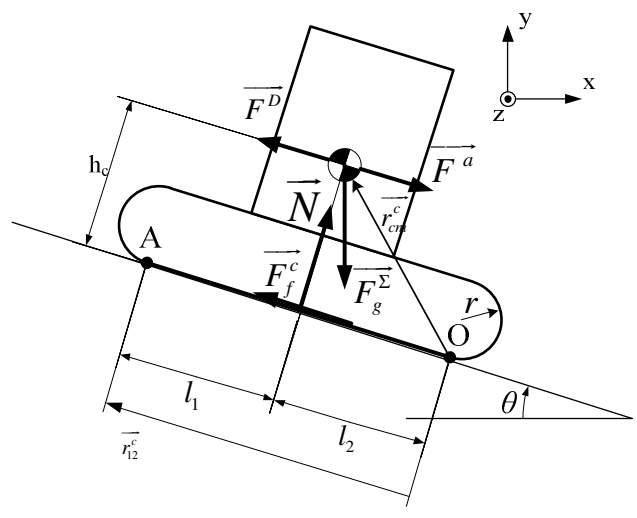

Figure 2 . Vehicle model

The loaded vehicle can be modeled as illustrated in Figure 2. Mass M, with a moment of inertia $I_{c m}$ about its center of mass. The forces acting on $\mathrm{M}$ are the gravitational force $\overrightarrow{F_{g}^{\Sigma}}=M \vec{g}$, the surface normal reaction force $\vec{N}$, friction force $\overrightarrow{F_{f}^{c}}$, driving force $\overrightarrow{F^{D}}$, inertial force $\overrightarrow{F^{a}}$, length of the contact surface $l_{c}=l_{1}+l_{2}$.

\subsection{The statistical stability}

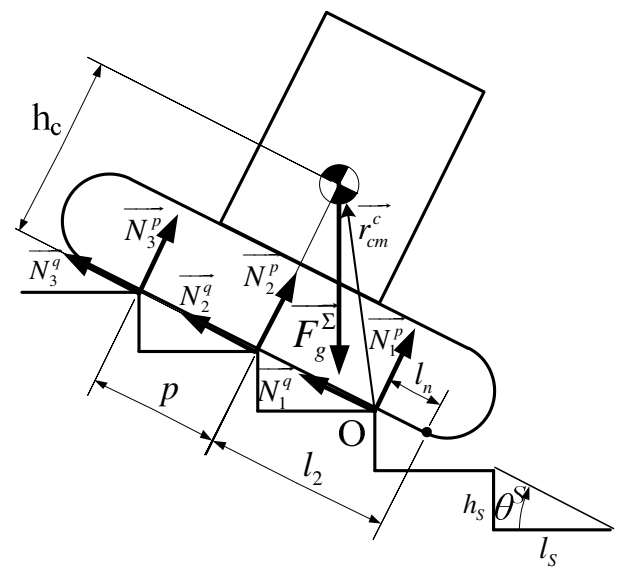

Figure 3 . Stair climbing model 
When the vehicle is stationary or moving without acceleration, system can be modeled as illustrated in Figure 3. In case of vehicle upstairs, the forces acting on $\mathrm{M}$ are the gravitational force $\overrightarrow{F_{g}^{\Sigma}}=m \vec{g}$, at each peak, there are two perpendicular forces $\overrightarrow{N_{i}^{q}}$ and $\overrightarrow{N_{i}^{p}},(i=1,2,3 \ldots)$. Angle of the ladder in this case is given by: $\tan \theta^{s}=\frac{h_{s}}{l_{s}}, h_{s}$ and $l_{s}$ are the height and width of each ladder, $p$ is the distance between the nearest peaks of the ladder and given by: $p=\sqrt{h_{s}^{2}+l_{s}^{2}}$.

The point of rotation will be about the downhill contact point $\mathrm{O}$. Torque equation can be written as:

$\operatorname{Mg}\left(h_{c} \cdot \sin \theta^{S}-\left(l_{2}-l_{n}\right) \cos \theta^{s}\right)-\sum\left|\overrightarrow{N_{i}^{p}}\right|(i-1) p=0$ (1) At the limit of stability, $\overrightarrow{N_{i}^{p}}=\overrightarrow{0}$ as point 2,3 just lifts away from the stair, $l_{2}<l_{n}$ equation (1) can be simplified into:

$$
\tan \theta_{c r i t 2}^{S}=\frac{l_{2}-p}{h_{c}}<\tan \theta^{S}=\frac{l_{2}-l_{n}}{h_{c}}
$$

Equation (2) gives the tipping stability limit, the angle $\theta_{\text {crit } 2}^{s}\left(\tan \theta_{c r i t 2}^{s}=\frac{l_{2}-p}{h_{c}}\right)$ at which the vehicle first starts to tip over depends on $l_{2}$.

Similarly, in case of vehicle moves down the stairs (illustrated in Figure 4. The tipping stability limit, the angle $\theta_{c r i t 1}^{s}\left(\tan \theta_{c r i t 1}^{s}=\frac{l_{2}-p}{h_{c}}\right)$ at which the vehicle

first starts to tip over depends on $l_{1}$ :

$$
\tan \theta^{S}=\frac{l_{1}-l_{n}}{h_{c}}<\tan \theta_{c r i t 1}^{s}=\frac{l_{1}-p}{h_{c}}
$$

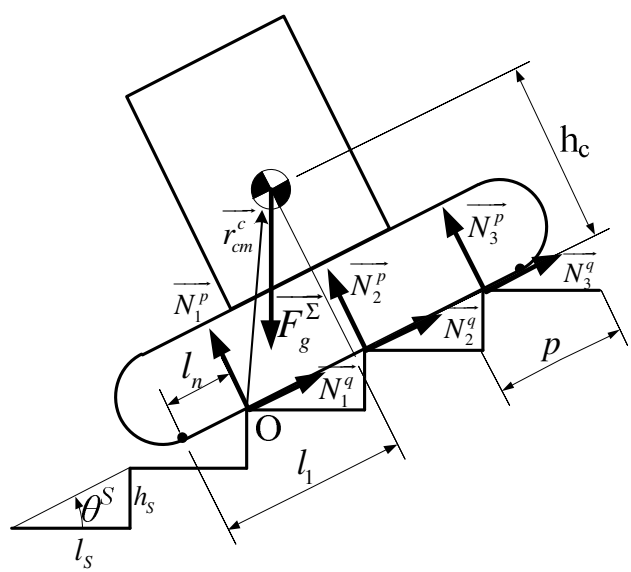

Figure 4 . Stair descending model

It is concluded that the vehicle moves stablity if the gravitational force $\overrightarrow{F_{g}^{\Sigma}}$ located in the space limited by the angle $\theta_{\text {crit } 1}^{S}$ and $\theta_{\text {crit } 2}^{S}$, (illustrated in Figure 5).

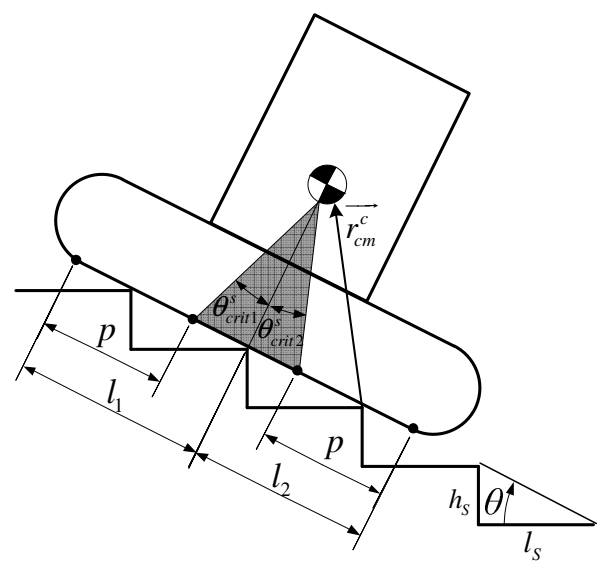

Figure 5 . Limit of stable space 


\subsection{The effect of the veclocity}

When the vehilce when moving down the stairs with veclocity $\overrightarrow{v_{0}}$, certainly, the angular velocity is zero $\omega_{0}=0$. If for any reason the vehicle stop suddenly, vehicles can be flipped forward, shown in Figure 6. The next section will analyze the conditions for vehicle overturned in this case. To facilitate the calculation, assuming that no loss of energy when the vehicle brake suddenly.

Subscript 0 refers to the situation immediately prior to impact, The movement of vehicle include only translational motion with initial veclocity $v_{0}$. Kinetic and potential energy of the vehicle at this time, $T_{0}$ và $V_{0}$.
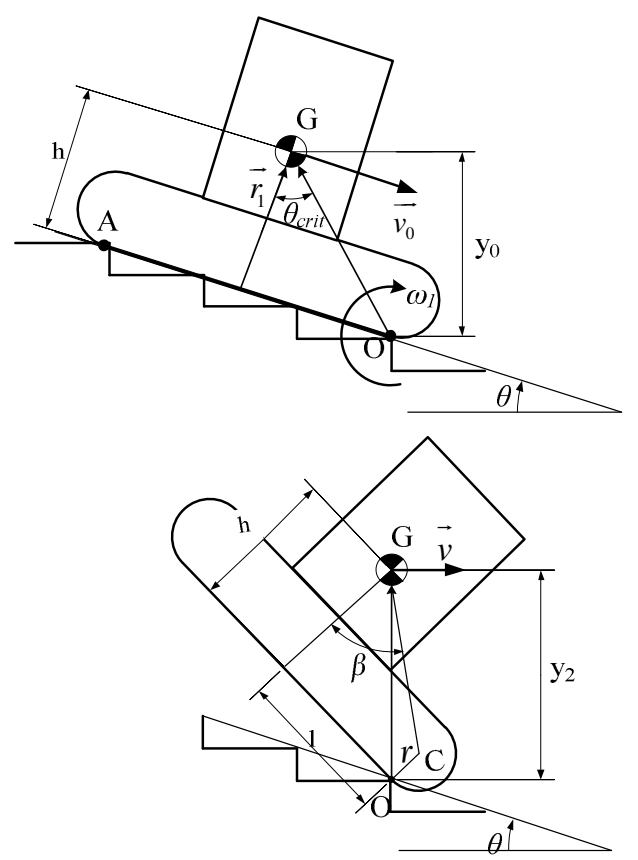

Figure 6 Vehicle collision
Subscript 1 refers to the situation immediately after impact. The movement of vehicle include only translational motion with initial veclocity $v_{0}$ and rotational motion with angular velocity $\omega_{0}$. At this time, center of gravity height : $y_{1}=y_{0}$. Kinetic and potential energy of the vehicle at this time, respectively $T_{1}$ and $V_{1}$.

Subscript 2 refers to the situation some time after impact. Center of gravity is highest positon at this time $\left(y_{2}\right)$. Kinetic and potential energy of the vehicle at the time, respectively $T_{2}$ and $V_{2}$.

The energy of the vehicle at 0 is given by: $T_{0}+V_{0}=\frac{1}{2} M v_{0}^{2}+M g y_{0}$, The energy of the vehicle at 2 includes $T_{2}$ and $V_{2}$. Applying conservation of energy postimpact: $\frac{1}{2} M v_{0}^{2}+M g y_{0}=T_{2}+V_{2}$.

Applying the principle of conservation of angular momentum $(\mathrm{O}),\left(I_{1}\right.$ is inertia moment of system):

$$
\left(M v_{0}\right) h=(M v)\left|\vec{r}_{1}\right|+I_{1} \omega_{1}
$$

Because the vehicle starts rotating about the instantaneous velocity of the vehicle $\mathrm{O}_{1}$ when the center of gravity at the highest position, we consider that: $v_{1}=\left|\vec{r}_{1}\right| \omega_{1}$. Combining this expression with equation (3) leads to: 


$$
\left(M v_{0}\right) h=\left(M\left|\vec{r}_{1}\right|^{2}+I_{1}\right) \omega_{1}
$$

Kinetic of system immediately prior to impact is given by:

$$
T_{0}=\frac{1}{2} M v_{0}^{2}
$$

Kinetic of system immediately after impact is given by:

$T_{1}=\frac{1}{2} M v_{1}^{2}+\frac{1}{2} I_{1} \omega_{1}^{2}=\frac{1}{2}\left(M\left|\vec{r}_{1}\right|^{2}+I_{1}\right) \omega_{1}^{2}$

Applying conservation of energy post-impact at subscript 1 and 2:

$$
T_{1}+V_{1}=T_{2}+V_{2}
$$

The potential energy of the vehicle at 1 and 2, respectively $: V_{1}=M g y_{1}=M g y_{0}$, $V_{2}=M g y_{2}$, Kinetic energy of the vehicle at 2 is zero: $T_{2}=0$

By solving equation (6), we can calculate the conditions required to induce unrecoverable tipping of the vehicle, where the vehicle's tilt angle in world co-ordinates has reached the limit of statistical stability $\theta_{\text {crit }}^{S}$ with zero speed. Tipping of the vehicle up to this point will be recoverable, as the vehicle will be statistically stable even at maximum tip, and hence recover its initial position and orientation.

Equation (5) is re-written as:

$$
\begin{aligned}
& \left(M v_{0}\right) h=\left(M\left|\vec{r}_{1}\right|^{2}+I_{1}\right) \omega_{1} \\
\Leftrightarrow \quad & \left(M v_{0} h\right)^{2}=\left(M\left|\vec{r}_{1}\right|^{2}+I_{1}\right)^{2} \omega_{1}^{2} \\
\Leftrightarrow & \frac{\left(M v_{0} h\right)^{2}}{\left(M\left|\vec{r}_{1}\right|^{2}+I_{1}\right)}=\left(M\left|\overrightarrow{r_{1}}\right|^{2}+I_{1}\right) \omega_{1}^{2}
\end{aligned}
$$

Combining this expression with equation (6) leads to :

$$
T_{1}=\frac{1}{2} \frac{\left(M v_{0} h\right)^{2}}{\left(M\left|\overrightarrow{r_{1}}\right|^{2}+I_{1}\right)}
$$

Combining this expression with equation (5) leads to :

$$
\frac{1}{2} \frac{\left(M v_{0} h\right)^{2}}{\left(M\left|\overrightarrow{r_{1}}\right|^{2}+I_{1}\right)}=M g\left(y_{2}-y_{1}\right)
$$

Solving for $v_{\text {tilt }}^{c}=v_{0}$ gives us:

$v_{\text {tilt }}^{c}=v_{0}=\sqrt{\frac{2 g\left(y_{2}-y_{1}\right)\left(M\left|\vec{r}_{1}\right|^{2}+I_{1}\right)}{M h^{2}}}$

In addition to increased stability, maximum amount of tip $\Delta y$ which is generated upon tipping, which is a measure of how much time the wheelchair's wheels spend off the ground and out of play as control surfaces for the wheelchair. $\Delta y=y_{2}-y_{1}$.Solving equation (2.25), we have:

$\Delta y=\frac{M v_{0}^{2} h^{2}}{2 g\left(M\left|\overrightarrow{r_{1}}\right|^{2}+I_{1}\right)}=\frac{T_{0}}{g} \frac{h^{2}}{\left(M\left|\overrightarrow{r_{1}}\right|^{2}+I_{1}\right)}$

The ratio of change in potential energy $\Delta V$ at maximum tilt to kinetic energy $T_{0}$ on impact (illustrated in Figure 6). 


$$
\begin{aligned}
& \frac{\Delta V}{T_{0}}=\frac{M h^{2}}{\left(M\left|\overrightarrow{r_{1}}\right|^{2}+I_{1}\right)}=\frac{M h^{2}}{\left(M h^{2}+I_{1}\right)} \\
& \Leftrightarrow \frac{\Delta V}{T_{0}}=\frac{1}{1+\frac{I_{1}}{M h^{2}}}<1
\end{aligned}
$$

The ratio of equation (12) calculates the fraction of the kinetic energy originally available which is not dissipated in the plastic collision, and hence the ratio is always less than unity.

\subsection{The effect of the accelaration}

When the vehicle is stationary or moving with acceleration $\vec{a}$, system can be modeled as illustrated in Figure7. The forces acting on M include the gravitational force $\overrightarrow{F_{g}^{\Sigma}}=m \vec{g}$, the surface normal reaction force $\vec{N}$, and inertia force $M \cdot \vec{a}$

The point of rotation will be about the downhill contact point $\mathrm{O}$. Torque equation can be written as:

$$
\begin{aligned}
& M g\left(-h \cdot \sin \theta^{S}+\left(l_{2}-l_{n}\right) \cos \theta^{S}\right)-\sum\left|\overrightarrow{N_{i}^{p}}\right|(i-1) p \\
& - \text { M.a.h } h=0
\end{aligned}
$$

At the limit of stability, $\overrightarrow{N_{i}^{p}}=\overrightarrow{0}$ as point 2,3 just lift away from the stair, (13) simplifies into:

$$
\sin \left(\theta^{S}-\gamma\right)=\frac{a \cdot h}{g \sqrt{h^{2}+\left(l_{2}-l_{n}\right)^{2}}}
$$

With $\sin \gamma=\frac{l_{2}-l_{n}}{\sqrt{h^{2}+\left(l_{2}-l_{n}\right)^{2}}}$
Adding safely factor $k$ into equation, equation (14) can be rewritten as: $M g\left(h \cdot \sin \theta^{S}-\left(l_{2}-l_{n}\right) \cos \theta^{s}\right)-\sum\left|\overrightarrow{N_{i}^{p}}\right|(i-1) p$ $-k \cdot M \cdot a \cdot h=0$

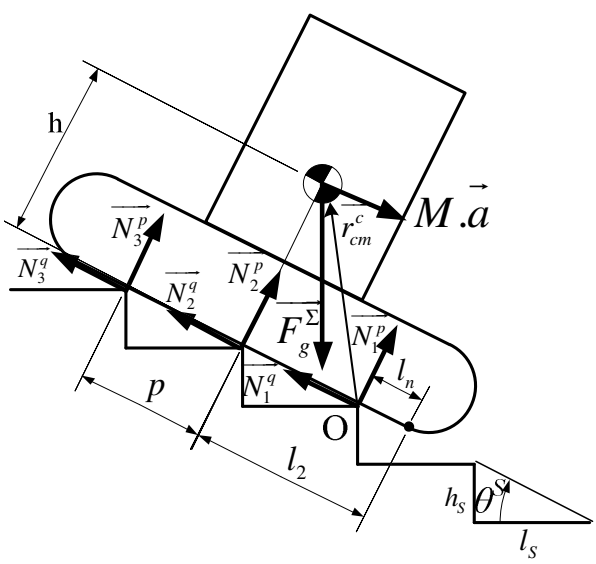

Figure 7 . The effects of acceleration.

Equation (14) can be simplied into:

$\sin \left(\theta^{S}-\gamma\right)=\frac{k \cdot a \cdot h}{g \sqrt{h^{2}+\left(l_{2}-l_{n}\right)^{2}}}$

Equation (16) gives the dynamic stability limit.

\section{CONCLUSION}

This paper has determined the effects of mass, velocity, acceleration of the vehicle using tracks (chain, belt) while climbing and descending stairs. The conditions such as $v_{\text {tilt }}^{c}$, $\theta_{\text {crit } 1}^{S}$ and $\theta_{\text {crit } 2}^{S}, a$ depend on the size of stairs, shape of the vehicle. Determining the stability limits while stair climbing and descending should be considered in calculation of the size parameters of tracked driven vehicles(robots). 


\section{XÁC ĐỊNH ĐIỀU KIỆN ỔN ĐỊNH CỦA CÁC LOẠI XE DI CHUYỂN TRÊN BẬC THANG DÙNG DÂY XÍCH}

Phạm Đức Khôi, Thái Thị Thu Hà

DCSELAB, University of Technology, VNU-HCM

ABSTRACT: Bài viết này trình bày cơ sở lý thuyết và phuơng pháp xác định giới hạn ổn định của các loại robot(hoặc xe lăn chạy điện) dùng cơ cấu dây bám (dây xích, dây đai)trong khi di chuyển lên xuống cầu thang. Phuoong pháp nghiên cứu truơớc hết là mô hình hóa xe (robot) khi làm việc duới ảnh hưởng yếu tố hình học, khối luợng, vận tốc, gia tốc, ma sát. Sau đó xác định các dạng mất ổn định và các điều kiện giới hạn mà ở đó xe bắt đầu bị lật nghiêng. Cuối cùng kết quả của việc phân tích là tìm ra các phuơng trình co họ đảm bảo cho xe hoạt động ổn định.

Keywords: wheelchair

\section{REFERENCES}

[1]. Parris Wellman, Venkat Krovi, Vijay Kumar, William Harwin, Design of a wheelchair with Legs for People with Motor Disabilities, Ieee Transactions On
Rehabilitation Engineering. 3, 343 - 352

(1995).

[2]. INDEPENDENC iBOT Mobility System, Independence Technology, L.L.C. P.O.

Box 7338, Endicott, NY13760, http://www.ibotnow.com (2007). 